\title{
Hemodynamic and ventilatory changes during implant surgery with intravenous conscious sedation
}

\author{
Sandra González-Lemonnier ${ }^{1}$, Maite Bovaira-Forner ${ }^{2}$, David Peñarrocha-Diago ${ }^{3}$, María A. Peñarrocha- \\ Diago ${ }^{4}$
}

\footnotetext{
${ }^{1}$ Master of Oral Surgery and Implantology. Valencia University Medical and Dental School. Valencia

${ }^{2}$ Specialist in Anesthesiology and Resuscitation. Levante Rehabilitation Center. Valencia

${ }^{3}$ Student of the Master of Oral Surgery and Implantology. Valencia University Medical and Dental School

${ }^{4}$ Associated Professor of Oral Surgery. Valencia University Medical and Dental School
}

Correspondence:

Facultad de Medicina y Odontología,

Gascó Oliag 1,

46021 Valencia (Spain)

maria.penarrocha@uv.es

Received: 01/03/2010

Accepted: $31 / 05 / 2010$

\author{
González-Lemonnier S, Bovaira-Forner M, Peñarrocha-Diago D, Peña- \\ rrocha-Diago MA. Hemodynamic and ventilatory changes during im- \\ plant surgery with intravenous conscious sedation. Med Oral Patol Oral \\ Cir Bucal. 2011 Jul 1;16 (4):e541-5. \\ http://www.medicinaoral.com/medoralfree01/v16i4/medoralv16i4p541.pdf \\ Article Number: $16911 \quad$ http://www.medicinaoral.com/ \\ (C) Medicina Oral S. L. C.I.F. B 96689336 - pISSN 1698-4447 - eISSN: 1698-6946 \\ eMail:medicina@medicinaoral.com \\ Indexed in: \\ Science Citation Index Expanded \\ Journal Citation Reports \\ Index Medicus, MEDLINE, PubMed \\ Scopus, Embase and Emcare \\ Indice Médico Español
}

\begin{abstract}
Purpose: This study was conducted to determine the hemodynamic and ventilatory changes during implant surgery with intravenous conscious sedation, and whether preoperative anxiety, gender or age influence these parameters.

Patients and Methods: A prospective study carried out between May 2004 and February 2007, on 102 patients treated with dental implants under local anesthesia and conscious intravenous sedation. Patients completed a questionnaire prior to surgery to evaluate preoperative dental anxiety using Corah's scale. The hemodynamic and ventilatory changes were evaluated by monitoring systolic pressure (SP), diastolic pressure (DP), heart rate (HR) and oxygen saturation $(\mathrm{SaO} 2)$. These values were collected at 5 points during surgery; before commencing the operation (baseline value), during local anesthetic injection, at the moment of incision and raising of a mucoperiosteal flap, during implant placement, and finally at suturing. Intravenous conscious sedation was administered between baseline value and injection of the local anesthetic.

Results: The highest SP and DP were recorded at baseline and at suturing. The highest HR was recorded at the moment of incision and raising of the mucoperiosteal flap; the lowest $\mathrm{SaO} 2$ was recorded at local anesthetic injection. There was no relationship between hemodynamic and ventilatory values and preoperative anxiety or gender. A greater age was associated with higher $\mathrm{SP}$ and lower $\mathrm{SaO} 2$, these differences being statistically significant. Conclusions: Most of the cardiovascular and ventilatory changes induced by the implant surgery with intravenous conscious sedation were within normal ranges. The results indicate that midazolam with fentanyl do not produce important hemodynamic and ventilatory changes, being a good association for intravenous conscious sedation in dental implant surgery.
\end{abstract}

Key words: Hemodynamic changes, dental implants, conscious sedation. 


\section{Introduction}

The term conscious sedation represents a drug-induced state in which the conscious patient is rendered free of fear, anxiety, and apprehension while remaining comfortably relaxed. Conscious sedation is not a method of pain control (1). Dental anxiety and pain can lead to hemodynamic changes such as hypertension or increased heart rate which can be controlled with a correct sedation technique. In dental implant surgery, where a very long procedure is expected, local anesthesia may be insufficient to perform an adequate operation, and conscious intravenous sedation is an option (2). The administration of intravenous conscious sedation by the anesthetist is safe and results in a low incidence of adverse events (3). Alemany-Martínez et al. (4), evaluated the hemodynamic changes during the surgical removal of lower third molars, and concluded that most of the cardiovascular changes induced by surgical extraction of molars were within normal ranges. Parworth et al. (5), during third molar surgery, administered propofol and fentanyl in one group and midazolam and fentanyl in another. Systolic and diastolic blood pressure were lower in both groups at the 5-minute intraoperative period, these differences being statistically significant. Both groups showed a significant increase in heart rate at the 10 - and 15-minute periods. Average oxygen saturation remained above $99 \%$ at the 5 -minute intraoperative periods during the entire procedure in both groups. They concluded that the differences in systolic and diastolic pressure, heart rate and oxygen saturation were not clinically important, and no intervention was required.

The aim was to study the changes in blood pressure (systolic and diastolic), heart rate, and oxygen saturation under intravenous conscious sedation during implant surgery. We evaluated the influence of patient preoperative anxiety, gender and age on these changes.

\section{Material and Methods}

A prospective study was made on 102 patients treated with dental implants under local anesthesia and conscious intravenous sedation between May 2004 and February 2007. Indication for conscious intravenous sedation was the placing of 4 or more implants or if surgery was to last more than 60 minutes. The inclusion criteria were patients in ASA I-II-III, requiring implants with local anesthesia and intravenous conscious sedation. Exclusion criteria were incomplete questionnaires returned by the patients.

Patients were instructed to fast for 6 hours before their appointment and to bring a responsible person to accompany them home after sedation. All patients were treated in a clinic equipped with the appropriate sedation and monitoring facilities.

Before surgery, in the waiting room, patients completed a questionnaire to evaluate preoperative dental anxiety using Corah's scale (6). The questionnaire contains 4 items on different feelings concerning dental consultation. Each question has 5 possible answers, ranging from a) $=1$ (no anxiety) to e) $=5$ (high anxiety). Therefore, the possible score ranges from 4 to $20(7,8)$. Anxiety is considered low when scores are equal to or less than 6 , moderate with scores between 7 and 12, and high with scores equal to or greater than 13 (9).

The procedure was carried out by the same surgeon and anesthetist. The protocol for administration of conscious sedation was: midazolam $0.05 \mathrm{mg} / \mathrm{kg}$ and fentanyl $1 \mu \mathrm{g} / \mathrm{kg}$; the local anesthetic was administered once good sedation had been achieved. In all cases articaine $4 \%$ with a vasoconstrictor (adrenaline 1:200,000) was used. If the patient remained tense propofol $20-30 \mathrm{mg}$ was added.

Anesthesia was maintained with midazolam $1 \mathrm{mg}$ and fentanyl $0.5-1 \mu \mathrm{g} / \mathrm{kg}$, every 30 or 60 minutes in function of patient state and anesthetic depth. If necessary, propofol was administered on demand in successive bolus of $20 \mathrm{mg}$. Atropine $0.01 \mathrm{mg} / \mathrm{kg}$ was administered to patients under 30 years of age or with a basal heart rate lower than $60 \mathrm{bpm}$ when no contraindicating medication was present.

The hemodynamic and ventilatory changes were evaluated by monitoring systolic pressure (SP), diastolic pressure (PD), heart rate (HR) and oxygen saturation (SaO2). These values were collected at 5 moments; before commencing surgery (baseline value), during local anesthetic injection, at the moment of incision and raising a mucoperiosteal flap, during placement of implants and finally at suturing. Intravenous conscious sedation was administered after obtaining the baseline value and before local anesthetic injection.

The SPSS version 15.0 (SPSS Inc, Chicago, IL) was used for all statistical analyses. Statistical significance was considered for $\mathrm{p}$ values less than .05 in all cases. Mixed ANOVAS were made with a repeated means factor (phases of surgical procedure), and another factor between characters (sex, anxiety). Age was analyzed with Pearson's correlation.

\section{Results}

Twelve patients were excluded for returning incomplete questionnaires. The final study comprised ninety patients (57 women and 33 men; mean age 54.1 years [range, 27 to 85]) who underwent implant surgery with conscious intravenous sedation. Six hundred ninetythree implants were placed (mean 7.7 implants per patient). Average time of surgical procedure was 98 minutes.

The highest SP and DP were recorded at baseline and at suturing. The highest HR was recorded at the moment of incision and raising of the mucoperiosteal flap, and the lowest $\mathrm{SaO} 2$ was recorded at the local anesthetic 
A. Systolic pressure

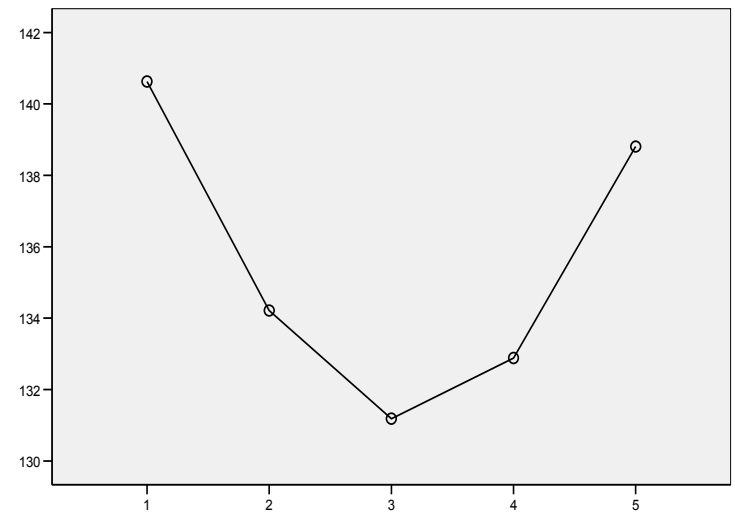

C. Heart rate

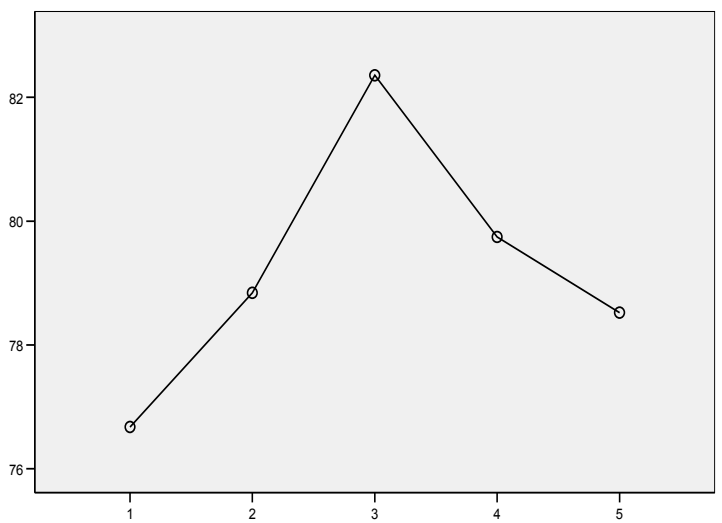

B. Diastolic pressure

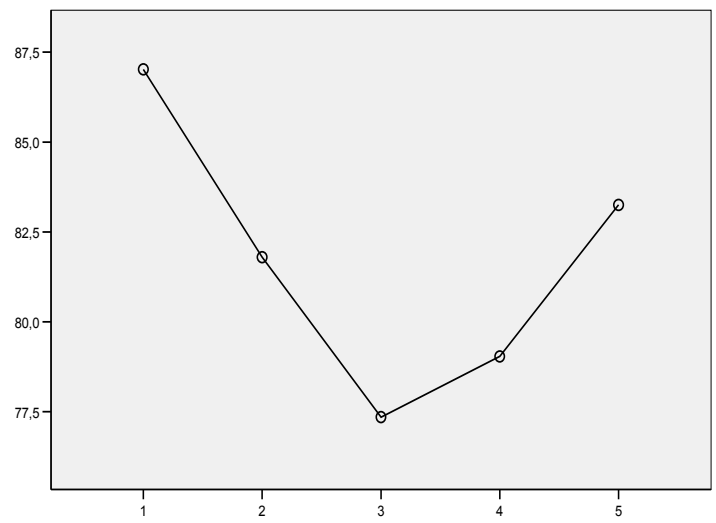

D. Oxygen saturation

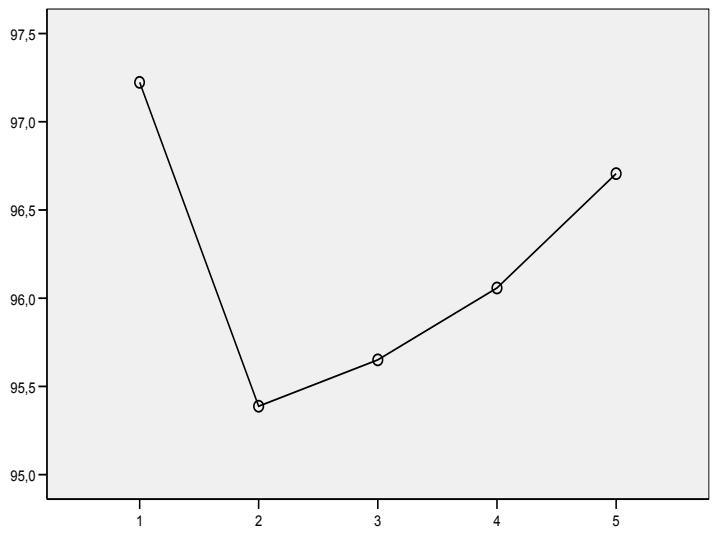

Fig. 1. Hemodynamic-ventilatory evolution (A. Systolic pressure; B. Diastolic pressure; C. Heart rate; D. Oxygen saturation) during the surgical procedure. Numbers represent each stage of the surgery (1. Baseline value; 2. Local anesthetic injection; 3 . Incision and raising of mucoperiosteal flap; 4. Placement of implants; 5. Suturing). SP and DP are expressed in $\mathrm{mmHg}$, HR in bpm and $\mathrm{SaO} 2$ is expressed as percentage.

injection. Fig. 1 shows the evolution of SP, DP, HR and $\mathrm{SaO} 2$ during surgery.

Regarding SP and DP, there was a statistically significant decrease between baseline value and the incision and raising of the mucoperiosteal flap ([SP; $d=9.45$; $\mathrm{p}<0.001]$ and [DP; $d=9.67 ; \mathrm{p}<0.001])$, and a statistically significant increase between placement of implants and suturing ([SP; $\mathrm{d}=-5.92 ; \mathrm{p}=0.019]$ and [DP; $\mathrm{d}=-4.21$; $\mathrm{p}=0.012]$. There was a statistically significant increase in HR between baseline value and the incision and raising of the mucoperiosteal flap $(\mathrm{d}=-5.68 ; \mathrm{p}<0.001)$ and a statistically significant decrease between the incision and raising of the mucoperiosteal and suturing $(\mathrm{d}=3.83$; $\mathrm{p}=0.008)$. $\mathrm{SaO} 2$ decreased significantly between base- line value and the incision and raising of the mucoperiosteal flap $(\mathrm{d}=1.57 ; \mathrm{p}<0.001)$, and significantly increased between local anesthetic injection and suturing $(\mathrm{d}=$ $1.32 ; \mathrm{p}=0.001$ ).

Table 1 shows the hemodynamic and ventilatory values in relation to preoperative anxiety and gender. A lower preoperative patient anxiety was associated with highest SP and DP, and lowest $\mathrm{SaO} 2$. Patients with high preoperative anxiety showed highest HR. Men showed higher SP and DP values than women.

There was no relationship between hemodynamic and ventilatory values and preoperative anxiety and gender. A greater age was associated with higher $\mathrm{SP}$ and lower $\mathrm{SaO} 2$, these differences being statistically significant (Table 2). 
Table 1. Hemodynamic and ventilatory values in relation to preoperative anxiety and gender.

\begin{tabular}{|l|c|c|c|c|c|}
\hline $\begin{array}{c}\text { Hemodynamic ventilatory } \\
\text { value }\end{array}$ & \multicolumn{3}{|c|}{ Preoperative anxiety } & \multicolumn{2}{c|}{ Gender } \\
\hline & Low & Moderate & High & Women & Men \\
\hline Systolic pressure & $137.2 \pm 3.8$ & $132.7 \pm 2.8$ & $134.7 \pm 4.2$ & $131.4 \pm 2.5$ & $139.6 \pm 3.2$ \\
\hline Diastolic pressure & $81.9 \pm 1.9$ & $80.54 \pm 1.4$ & $80.5 \pm 2.1$ & $78.8 \pm 1.2$ & $84.5 \pm 1.6$ \\
\hline Heart rate & $76.6 \pm 2.2$ & $80.6 \pm 1.6$ & $82.8 \pm 2.5$ & $82.2 \pm 1.5$ & $76.2 \pm 1.9$ \\
\hline Oxygen saturation & $95.7 \pm 0.3$ & $96.2 \pm 0.3$ & $97.2 \pm 0.4$ & $96.6 \pm 0.2$ & $95.8 \pm 0.3$ \\
\hline
\end{tabular}

Table 2. Relationship between hemodynamic-ventilatory values and preoperative anxiety, gender and age.

\begin{tabular}{|l|c|c|c|c|c|c|}
\hline \multirow{2}{*}{$\begin{array}{c}\text { Hemodynamic-ventilatory } \\
\text { value }\end{array}$} & \multicolumn{1}{|c|}{ Preoperative anxiety } & \multicolumn{2}{|c|}{ Gender } & \multicolumn{2}{c|}{ Age } \\
\cline { 2 - 7 } & P & F & p & F & p & r \\
\hline Systolic pressure & 0.42 & 1.01 & 0.79 & 0.36 & 0.004 & 0.30 \\
\hline Diastolic pressure & 0.29 & 1.22 & 0.69 & 0.51 & 0.16 & 0.15 \\
\hline Heart rate & 0.97 & 0.26 & 0.60 & 0.66 & 0.082 & -0.18 \\
\hline Oxygen saturation & 0.97 & 0.12 & 0.29 & 1.25 & 0.001 & -0.36 \\
\hline
\end{tabular}

\section{Discussion}

Systolic pressure (SP) was observed to decrease significantly before local anesthetic injection, coinciding with the administration of intravenous conscious sedation. These results agree with Paramaesvaran and Kingon (10) and Yokobayashi et al. (11). These authors obtained the same results as Parworth et al. (5), who administered propofol and fentanyl in one group and midazolam and fentanyl in another during third molar surgery, showing a significant decrease in SP 5 minutes into surgery in both groups. In contrast, SP increased for Liau et al. (12) in patients undergoing simple extractions.

Diastolic pressure (DP) increased for Liau et al (12) and decreased for other authors during administration of local anesthetic $(10,11)$. The latter results agree with our study, where a significant decrease in DP was observed before local anesthetic injection, coinciding with the administration of intravenous conscious sedation.

In a study by Paramaesvaran and Kingon (10), and Yokobayashi et al. (11), the heart rate (HR) decreased during the administration of local anesthetic. In our study we observed an increase in HR during injection of local anesthetic, results which agree with Liau et al. (12) and Parworth et al. (5).
Liau et al. (12) propose that the increase in blood pressure and HR during injection of local anesthetic could be due to the release of endogenous adrenaline resulting from emotional stress, and not to the effect of local anesthetic. In our study, we used a local anesthetic (articaine) associated with a vasoconstrictor (adrenaline 1:200,000) after administration of conscious sedation, observing a significant decrease in SP, DP and $\mathrm{SaO} 2$ and a moderate increase in HR.

In the study by Parworth et al. (5), oxygen saturation remained at over $99 \%$ in all surgeries. Garip et al. (13), administered only midazolam in one group and midazolam with remifentanil in another during operations on third molars. They observed that none of the midazolam only group had saturation below $97 \%$, and in the midazolam with remifentanil group 10 of 20 patients had saturation below $95 \%$. In the present study, oxygen saturation remained at over $95 \%$ during all operations. For Liau et al. (12), patients with high anxiety had higher SP, DP and HR values, demonstrating that dental anxiety is related with hemodynamic and ventilatory changes. In agreement with these authors, Silvestre et al. (14), using 3 different local anesthetics for molar extractions, showed that patients with more anxiety had an increase 
in SP and DP. In a study by Alemany-Martínez et al. (4), during surgical removal of lower third molars without intravenous conscious sedation, patients with high anxiety showed lower SP and DP and higher HR, although the differences were not statistically significant. In our study, in agreement with Alemany-Martínez et al. (4), there was no significant relationship between hemodynamic and ventilatory values and preoperative anxiety. Patients with greater anxiety showed lower SP, DP and $\mathrm{SaO} 2$ values and higher HR. Association between emotional stress and tachycardia due to secondary adrenergic release may explain these effects (15).

For Alemany-Martínez et al. (4), men showed higher SP and DP than women, although lower HR. In the present study, using intravenous conscious sedation, there was no significant relationship between sex and hemodynamic and ventilatory changes. SP and DP were higher in men, and HR higher in women. $\mathrm{SaO} 2$ was lower in men.

Regarding age, in a study by Matsumura et al. (16), patients in middle and advanced age had a greater increase in SP and DP during molar extractions than younger patients. In agreement with these authors, Nagao et al. (17), in dental implant surgery under local anesthesia, showed that SP increased with age. On the other hand, Alemany-Martínez et al. (4), observed no significant hemodynamic and ventilatory changes in their patients. In the present study, increased age was significantly associated with higher $\mathrm{SP}$ and lower $\mathrm{SaO} 2$; and also associated with higher DP and lower HR, but without statistical significance.

Hemodynamic and ventilatory values remained stable during dental implant surgery under intravenous conscious sedation. Older age was associated with a higher $\mathrm{SP}$ and lower $\mathrm{SaO}$. Hemodynamic and ventilatory values were not related with sex and preoperative anxiety. The results of this study indicate that midazolam with fentanyl do not cause important hemodynamic and ventilatory changes, being a good combination for intravenous conscious sedation in dental implant surgery.

\section{References}

\section{References with links to Crossref - DOI}

1. Bennett CR. Conscious sedation: an alternative to general anesthesia. J Dent Res. 1984;63:832-3.

2. Chanavaz M, Ferri J, Donazzan M. [Intravenous sedation in implantology]. Rev Stomatol Chir Maxillofac. 1997;98:57-61.

3. Rodgers SF. Safety of intravenous sedation administered by the operating oral surgeon: the first 7 years of office practice. J Oral Maxillofac Surg. 2005;63:1478-83.

4. Alemany-Martínez A, Valmaseda-Castellón E, Berini-Aytés L, Gay-Escoda C. Hemodynamic changes during the surgical removal of lower third molars. J Oral Maxillofac Surg. 2008;66:453-61.

5. Parworth LP, Frost DE, Zuniga JR, Bennett T. Propofol and fentanyl compared with midazolam and fentanyl during third molar surgery. J Oral Maxillofac Surg. 1998;56:447-53.

6. Corah NL. Development of a dental anxiety scale. J Dent Res. 1969:48:596.

7. Dailey YM, Humphris GM, Lennon MA. The use of dental anxiety questionnaires: a survey of a group of UK dental practitioners. $\mathrm{Br}$ Dent J. 2001:190:450-3

8. Erten H, Akarslan ZZ, Bodrumlu E. Dental fear and anxiety levels of patients attending a dental clinic. Quintessence Int. 2006;37:30410.

9. Zacny JP, Hurst RJ, Graham L, Janiszewski DJ. Preoperative dental anxiety and mood changes during nitrous oxide inhalation. J Am Dent Assoc. 2002;133:82-8.

10. Paramaesvaran M, Kingon AM. Alterations in blood pressure and pulse rate in exodontia patients. Aust Dent J. 1994;39:282-6.

11. Yokobayashi T, Nakajima T, Yagata H, Yatabe Y. Changes of heart rate during administration of local anesthetics in the oral region. J Oral Surg. 1977;35:961-7.

12. Liau FL, Kok SH, Lee JJ, Kuo RC, Hwang CR, Yang PJ, et al. Cardiovascular influence of dental anxiety during local anesthesia for tooth extraction. Oral Surg Oral Med Oral Pathol Oral Radiol Endod. 2008; 105:16-26.

13. Garip H, Gürkan Y, Toker K, Göker K. A comparison of midazolam and midazolam with remifentanil for patient-controlled sedation during operations on third molars. Br J Oral Maxillofac Surg. 2007;45:212-6.

14. Silvestre FJ, Verdú MJ, Sanchís JM, Grau D, Peñarrocha M. Effects of vasoconstrictors in dentistry upon systolic and diastolic arterial pressure. Med Oral. 2001;6:57-63.

15. Taggart P, Hedworth-Whitty R, Carruthers M, Gordon PD. Observations on electrocardiogram and plasma catecholamines during dental procedures: the forgotten vagus. Br Med J. 1976;2:787-9.

16. Matsumura K, Miura K, Takata Y, Kurokawa H, Kajiyama M, Abe I, et al. Changes in blood pressure and heart rate variability during dental surgery. Am J Hypertens. 1998;11:1376-80.

17. Nagao H, Munakata M, Tachikawa N, Shiota M, Kasugai S. [Clinical study of risk management for dental implant treatment--changes of blood pressure and pulse rate during implant surgery under local anesthesia]. Kokubyo Gakkai Zasshi. 2002;69:27-33. 